\title{
P-Glycoprotein Turned Twenty: Are We Any Closer to Fight Drug Resistance in Cancer?
}

D rug resistance of human tumors to a variety of chemotherapeutic agents represents a major cause of failure of cancer therapy. M ultiple mechanisms of drug resistance may occur in parallel or sequentially at all different levels of drug action, such as membrane-bound proteins that are involved in uptake or removal of drugs, cytoplasmic proteins that are involved in metabolism or detoxification of drugs, and nuclear proteins, involved in the repair of drug-induced DNA damage.

The most studied protein family is that of the transmembrane ATP-binding cassette (A BC) transporters which mediates drug resistance in tumor cells towards multiple drugs such as anthracyclines, vinca alkaloids, epipodophyllotoxines, taxanes, etc. The most prominent member of these multidrug resistance(M DR )associated proteins was identified two decades ago: P-glycoprotein [1], encoded by the multidrug resistance gene 1 (M D R 1). 'The high hope of P-glycoprotein was that here was a single protein that confers resistance to a whole array of structurally unrelated anti-cancer drugs. That was a very attractive idea. It raised the possibility that drug resistance could be overcome, because if a single mechanism is responsible, all you have to do is learn to understand that mechanism, find strategies to overcome it, and you could cure people of cancer' (J effrey A. M oscow, U niversity of K entucky M edical Center, L exington, U SA [2]). $B$ ased on this early optimism, a tremendous amount of laboratory and clinical studies was performed to provide evidence by conferring resistance using gene transfer of the MDR 1 gene, analyzing expression of P-glycoprotein in cancer cell lines, tumors, and normal tissues, and correlating these data to the clinical response and outcome. M ore importantly, various attempts have been made to reverse drug resistance with firstgeneration P-glycoprotein antagonists already in use for other indications, such as the calcium channel blocker verapamil and the immunosuppressive agent cyclosporin $A$, and meanwhile with second-generation modulators which were exclusively developed to overcome P-glycoprotein-mediated resistance. A dmittedly, a variety of problems slowed down the optimism of the early years: different expression profiles in certain tumors/tissues mainly caused by use of non-standardized procedures, varying correlation of expression and clinical response in certain cancers following chemotherapy, or partial lack of success of the first-generation P-glycoprotein modulators. However, 'By failing to face these challenges, we fail to ad- dress a mechanism of drug resistance that not only limits some of our most important convential chemotherapeutic agents but will undoubtedly limit new agents to come' (Susan E. B ates, National Cancer Institute, B ethesda, U SA [3]).

There are various reasons probably responsible for these disappointments: B esides the major player P-glycoprotein, a variety of further multidrug resistance-associated genes/proteins was identified in recent years; mainly the discovery of the multidrug resistance-associated protein MRP1 going along with its family members MRP2 to MRP 6 of this particular $A B C$ transporter family [4], the discovery of the so-called half-transporter BCR P/M XR/A BCP, which was simultaneously identified by three groups [5], the lung resistance protein LR P acting as the major vault protein in the nucleocytoplasmic transport [6], and of course, relatives of the P-glycoprotein itself [7]. Thus, the phenotype of multidrug resistance could not anymore be attributed to a sole, even well-characterized protein, but had to be understood as the net effect of a multifactorial process of an entire panel of resistance genes controlling an array of alternative resistance mechanisms.

H owever, there is no reason to be pessimistic, rather to be more patient, knowing that an enormous amount of advanced knowledge was collected over the past years: We do know a lot better how P-glycoprotein acts, we do know alternative mechanisms in M DR and in drug resistance in general showing different kinds of defensive strategies in the context of resistance. B asic biological knowledge of cell cycle genes, oncogenes and tumor suppressor genes, of genes involved in apoptotic processes, and of genes representing crucial points in signal transduction cascades is currently under re-evaluation in the focus of drug resistance [8]. A nd additionally, meanwhile we do have more sensitive and quantitative methods enabling us to improve detection of the desired genes, or even to identify new drug resistance-associated genes. Thus, we should be able to learn more about the regulation of the respective player in the drug resistance concert, about the interplay of the resistance-associated genes/proteins in signal transduction cascades, and about possible substitution of drug resistance mechanisms if a particular one is specifically blocked.

Since there is no escape, we have to face the polymorphism of drug resistance even in the current situation of emerging information. A possible way to deal with this in the near future

\begin{tabular}{ll}
\hline KARGER & @ 2000 S. K arger G mbH , Freiburg \\
Fax +497614520714 & A ccessible online at: \\
$\begin{array}{l}\text { E-mail Information@K arger.de } \\
\text { www.karger.com }\end{array}$ & www.karger.com/journals/onk \\
&
\end{tabular}

Dr. U Irike S. Stein

M ax-D elbrück-Centrum für M olekulare M edizin

und R obert-R össle-K linik, U niversitätsklinikum Charité

Lindenberger Weg 80, D-13125 B erlin (G ermany) 
might be the performance of studies analyzing an entire panel of drug resistance-associated genes which should be defined in a new, broader sense with highly sophisticated and standardized quantitative methods and controls in correlation analyses. Based on this, decisive candidate genes representing a broad panel of alternative resistance mechanisms are needed. Thus, a patient-individual profiling is desired which might provide the scientific basis for selection and application of specific chemotherapeutic drugs in cancer chemotherapy. These diagnostic tools should enable scientists and clinicians in different labs and hospitals to obtain comparative and more successful results in multicenter studies and, in parallel, would provide the rationale and the essential prerequisite for approches to overcome drug resistance.

The complexity of the phenomenon MDR and the two decades of intensive research raise the question: A re we any closer to fight drug resistance in cancer? The answer is: yes we are. However, addressing the question: A re we close enough to be as optimistic as two decades ago? The answer depends on the temper of the scientist, but might possibly be: certainly not, but we will proceed.

\section{References}

1 Riordan JR, Ling V: Purification of P-glycoprotein from the plasma membrane vesicles of Chinese hamster ovary cell mutants with reduced colchicine permeability. J Biol Chem 1979;254:12701-12705.

$2 \mathrm{R}$ eynolds $\mathrm{T}$ : R esearch on drug resistance unearths many molecules, many mechanisms. J N atl Cancer Inst 1998:20:1120-1122.

3 Bates SE : D rug resistance: Still on the learning curve. Clin Cancer Res 1999;5: 3346-3348.

4 B orst $P, E$ vers $R, K$ ool M, Wijnholds J : The multidrug resistance protein family. Biochim Biophys A cta 1999;1461:347-357.

$5 \mathrm{~K}$ uska B: A s easy as A B C: Scientists fish out another drug resistance gene. J $\mathrm{N}$ atl Cancer Inst 1999;91:402-404.

$6 \mathrm{D}$ alton WS, Scheper RJ: L ung resistance-related protein: determining its role in multidrug resistance. J N atl Cancer Inst 1999;91:1604-1605.

$7 \mathrm{~K}$ lein I, Sarkadi B, Varadi A : A n inventory of the human A BC proteins. Biochim Biophys A cta 1999;1461:237-262.

8 Shoemaker $\mathrm{R} \mathrm{H}: \mathrm{G}$ enetic and epigenetic factors in anticancer drug resistance. J $\mathrm{N}$ atl Cancer Inst 2000;92:4-5.

Ulrike S. Stein, B erlin 